\title{
A CONTRIBUIÇÃO DA ÁREA PRODUTIVA NO PROCESSO DE INOVAÇOEES TECNOLÓGICAS
}

José Carlos Barbieri

Professor do Departamento de Administração da Produção, Logística e de Operações Industriais da EAESP/FGV.

RESUMO: Não há dúvida de que as inovações tecnológicas estão entre as principais fontes de vantagens competitivas para uma quantidade crescente de empresas industriais. A primeira parte deste trabalho apresenta breves considerações sobre o processo de inovação tecnológica à medida que diferencia a inovação radical da incremental, dois tipos diferentes porém complementares de inovações. Na segunda parte é feita uma distinção conceitual entre duas abordagens para implementar inovações incrementais. Por último, discute-se o papel das atividades operacionais e das técnicas de gestão da produção no processo de inovação tecnológica, levando em consideração a nova abordagem relacionada com o movimento da qualidade total.

ABSTRACT: There is no doubt that technological innovations are one of the main source of competitive advantages for a growing number of industrial companies. The first part of this paper presents a brief appreciation of the innovation process while shows the differences between radical and incremental innovations, two distincts but complementary kinds of innovation. Then, a conceptual distinction between two approaches to set incremental innovations is analysed. Finally, this paper discusses the role of operation activities and production management tools in the technological innovation process, taking into consideration the new approach related to the total quality movement.

PALAVRAS-CHAVE: competitividade, inovação incremental, processo de implementação, melhorias contínuas, engenharia simultânea, inovação organizacional.

KEY WORDS: competitiveness, incremental innovation, implementation process, continuous improvements, simultaneous engineering, organizational innovation. 
A capacidade de realizar inovações tecnológicas de modo sistemático para responder às exigências do mercado é uma das principais dimensões competitivas das empresas. De um modo geral, os estudos sobre inovação tecnológica têm privilegiado as inovações de vulto e as questões pertinentes aos projetos de inovação, tais como os aspectos ligados à organização e direção de equipes de pesquisa, fatores de sucesso e de fracasso, avaliação e seleção de projetos, eliminação de barreiras comportamentais entre os diversos agentes envolvidos, interfaces problemáticas nas transferências dos resultados dos centros de pesquisa para as áreas operacionais, dificuldades nas interações entre instituições de ensino e pesquisa etc. Não há dúvida de que estes e outros aspectos dessa ordem são muito importantes e merecem a ênfase que tem sido dada a eles. Porém, os estudos sobre esta temática têm negligenciado a contribuição dos componentes administrativos e operacionais que integram os sistemas de gestão da produção enquanto fontes de inovação e enquanto parte importante do seu processo de implementação. A fase de implementação de uma inovação tecnológica envolve a criação de ferramentas, aquisição e preparação dos recursos de manufatura, produção inicial, sustentação comercial e outras atividades que estão entre as mais críticas de qualquer processo de inovação. $O$ modo como uma empresa administra a sua área produtiva pode facilitar ou dificultar a realização dessas atividades que, em geral, representam a maior parcela de dispêndios associados a este processo. A idéia central deste texto é a de que o uso de instrumentos apropriados de gestão da produção contribui de modo vigoroso para a realização sistemática de inovações tecnológicas na empresa, quer pela manutenção de um ambiente favorável às inovações de qualquer tipo, quer facilitando a introdução de melhorias ao longo do ciclo de vida de um produto ou processo inovado.

\section{INOVAÇÕES TECNOLÓGICAS}

A palavra inovação apresenta diversas acepções conforme a área de estudo ou a tradição de pesquisa que a utiliza. $\mathrm{Na}$ área mercadológica, inovação pode ser qualquer modificação percebida pelo usuário, mesmo que não ocorra nenhuma alteração física no produto. Nas áreas produtivas, inovação é a introdução de novidades materializadas em produtos, processos e serviços, novos ou modificados. Alguns estudos enfatizam as inovações que produzem grandes impactos econômicos ou que envolvem recursos vultosos e altos riscos. Por exemplo, Souder, ${ }^{1}$ após apresentar diversas definições de inovação extraídas da literatura, associa este termo às idéias de alto risco e que podem proporcionar elevados benefícios à organização que patrocina a sua implementação. Outros estudos enfatizam as bases do conhecimento que permitem a introdução das novidades. Para Betz, ${ }^{2}$ inovação é a introdução de novos produtos, processos e serviços no mercado e inovação tecnológica significa a introdução desses produtos, processos e serviços baseada em novas tecnologias. $\mathrm{Na}$ tradição dos estudos ligados à gestão tecnológica, a origem dos conhecimentos são importantes, daí a preocupação em diferenciar invenção da inovação da imitação e da difusão.

Neste trabalho, entendemos inovação tecnológica como um processo realizado por uma empresa para introduzir produtos e processos que incorporem novas soluções técnicas, funcionais ou estéticas. Estas soluções podem ser completamente novas pois não eram conhecidas ou usadas antes que a empresa inovadora as introduzisse. Neste caso, trata-se de uma inovação tanto para a empresa quanto para o setor produtivo globalmente considerado. Ou dito de outra forma, trata-se de inovações pioneiras que introduzem novidades absolutas. Por inovação pode-se entender também a introdu-
1. SOUDER, Willian E.. Managing new product innovations. Toronto: Lexinston Books, 1984, p. 3.

2. BETZ, Frederick. Managing technology. New Jersey: Prentice-Hall, 1987, p. 6. 
3. U. S. DEPARTMENT OF COMMERCE. Technological innovation: its environment and management. Washington (DC), 1967.

4. MANSFIELD, Edwin ; RAPAPORT, J.; SCHEENE, J. \& WAGNER, $\mathrm{S}$. Research and innovation in the modern corporation. New York: Macmillan, 1971, p. 118.

5. STEAD, H. The cost of technological innovation. Research Policy.v.5, p. 2-9, 1976

6. KAMIN, J. Y.; B|JAOUI, I. \& HORESH, R. Same determinants of cost distributions in the process of technological innovation. Research Policy. v.11, n.2, p. 83-94, abril 1982. ção dessas soluções por uma empresa, embora elas já fossem conhecidas ou utilizadas por outras. Neste caso, a novidade é relativa à empresa inovadora, pois as mudanças tecnológicas já estariam incorporadas em outras unidades produtivas.

As inovações, independentemente do fato de constituírem novidades absolutas ou relativas, podem se apresentar nas seguintes formas: 1) novo processo produtivo, ou alteração no processo existente, isto é, alterações em máquinas, equipamentos, instalações, métodos de trabalho etc., geralmente introduzidas com o objetivo de reduzir custos, melhorar a qualidade ou aumentar a capacidade de produção; 2) modificações no produto existente, ou a substituição de um modelo por outro, que cumpra a mesma finalidade básica, muitas vezes acrescidas de outras complementares; 3) introdução de novos produtos integrados verticalmente aos existentes, ou seja, fabricados a partir de um processo produtivo comum ou afim; 4) e introdução de novos produtos que exigem novas tecnologias para a empresa.

A inovação tecnológica é sempre uma atividade complexa e constituída de várias etapas, nas quais participam diversos agentes com diferentes papéis. Não é tarefa fácil determinar o início e o término de um processo de inovação. A grosso modo, esse processo vai desde a percepção de um problema ou oportunidade, técnica ou mercadológica, até a aceitação comercial do produto, serviço ou processo que incorpore as soluções tecnológicas encontradas. Em qualquer tipo de inovação a tecnologia pode ser produzida pela própria empresa inovadora, obtida de fontes externas, ou uma combinação destas duas primeiras. Essa última é a mais freqüente, pois, a independência nesta área, mesmo sendo possível, geralmente é antieconômica. Daí o intenso fluxo de transferência de tecnologia entre empresas e países, independentemente do seu grau de desenvolvimento científico e tecnológico, como ilustra a tabela 1.

Uma inovação que introduz novidades importantes para a empresa requer diversas atividades relacionadas com o processo de produção, envolvendo equipamentos, materiais, pessoal, serviços de apoio, procedimentos e programas operacionais. Por exemplo, aquisição e instalação de novos recur- sos de manufatura, ou adaptações nos recursos existentes; projeto e produção de ferramentas; análise e seleção de materiais e fornecedores; roteiros de fabricação, elaboração de instruções; treinamentos; definições sobre prazos, estoques, capacidade etc. Essas atividades, aqui denominadas genericamente de implementação, representam parcelas significativas dos custos de uma inovação, conforme mostraram diversos estudos. O famoso estudo promovido pelo U.S. Department of Commerce, ${ }^{3}$ realizado com base na opinião de vários especialistas em inovações tecnológicas (Charpie panel), estimou que estas atividades representavam entre 45 e $75 \%$ dos custos totais das inovações, enquanto a $\mathrm{P} \& \mathrm{D}$ representava entre 15 e $30 \%$ e a introdução comercial, entre 10 e $25 \%$. Mansfield et alii ${ }^{4}$ verificaram que a fase de implementação alcançava em média $46 \%$ dos custos totais de 38 inovações realizadas por empresas dos setores químico, eletrônico e de máquinas. Essa fase consumia em torno de $37 \%$ dos custos das inovações, de acordo com uma pesquisa realizada por Stead, ${ }^{5}$ no Canadá, e $33 \%$, na pesquiisa de Kamin, ${ }^{6}$ em Israel.

O percentual de recursos destinado à fase de implantação aumenta ainda mais quando a inovação de uma empresa se realiza basicamente com a introdução de novidades técnicas desenvolvidas por outras, configurando-se, dessa forma, um processo de

TABELA 1

Balanço de pagamentos de tecnologia: páises da OCDE selecionados ( 1992 ; em US \$ Milhöes)

\begin{tabular}{|l|r|r|r|}
\hline \multicolumn{1}{|c|}{ PAís } & RECEBIMEMTOS & PAGAMENTOS & \multicolumn{1}{c|}{ SALDO } \\
\hline Alemanha & $7,109.1$ & $10,125.2$ & $-3,116.1$ \\
Austrália & 202.7 & 351.8 & -149.1 \\
Austria & 122.3 & 418.9 & -296.6 \\
Bálgica & $2,386.2$ & $2,661.5$ & -275.3 \\
Canadá & 926.1 & 919.9 & 6.2 \\
Estudos Unidos & $19,922.0$ & $4,987.0$ & $14,935.0$ \\
Espanha & 791.2 & $3,171.3$ & $-2,380.1$ \\
Franģa & $2,012.4$ & $2,791.6$ & -779.2 \\
Itólia & $1,324.9$ & $2,404.8$ & $-1,079.9$ \\
Japōo & $2,982.2$ & $3,268.1$ & -286.0 \\
Países Baixos & $6,208.2$ & $6,138.9$ & 69.4 \\
Roino Unido & $2,846.7$ & $2,374.6$ & 471.1 \\
Suécia & 217.4 & 115.9 & 101.5 \\
\hline
\end{tabular}

Fonte: OCDE (1995), Stotisties on member countries (In: OCDE Observer, n. 194, jun.-jul. 1995, suplemento especial) 
difusão tecnológica. E essa é, sem dúvida, a situação mais freqüente, pois, como se sabe, apenas uma minoria de empresas realiza atividades próprias de $\mathrm{P} \& \mathrm{D}$. Esse é outro motivo que alimenta o intenso fluxo de tecnologia entre países exemplificado na tabela 1 . Além de dispendiosa comparativamente à $P \& D$, é na fase de implementação que são solucionadas diversas questões fundamentais para o sucesso das inovações, tais como, obtenção de flexibilidade para introduzir variações no modelo básico com o objetivo de atender diversos tipos de clientes, adaptações dos recursos ao tamanho do mercado, prazos de entrega, suporte aos serviços pósvenda e outras questões pertinentes à área de produção.

\section{Inovações Incrementais}

Qualquer processo de inovação só se completa quando as soluções técnicas estiverem definitivamente incorporadas aos produtos e processos. Nem sempre é fácil determinar quando um projeto de inovação importante está realmente concluído, pois esses produtos, processos e serviços, novos ou modificados, estarão recebendo diversas inovações de caráter incremental ao longo do seu ciclo de vida. Por isso não é tarefa fácil distinguir com clareza quando termina a inovação principal e começam os aperfeiçoamentos, que são formas complementares de inovação, mas nem por isso menos importantes.

De fato, numa pesquisa relatada por Marquis, ${ }^{7}$ em mais de 500 inovações estudadas, cerca de dois terços eram de pequena monta ( nuts and bolt ): custaram menos de US $\$ 100,000.00$ e contribuíram de modo significativo para o sucesso comercial das empresas que as realizaram. Um estudo sobre inovações em produtos realizado por Booz, Allen \& Hamilton ${ }^{8}$ mostrou que menos de $10 \%$ delas eram novas para o mundo; a maioria tratava de melhorias, adições em produtos existentes, reposicionamento do produto no mercado e redução de custo pela substituição de um produto por outro que atenda a mesma finalidade. Betz ${ }^{9}$ entende que as inovações incrementais mantêm a empresa continuamente inovadora $\mathrm{e}$ fornecem as bases para o planejamento da P\&D. Além disso, os impactos dessas inovações sobre as mudanças tecnológicas podem ter a mesma magnitude das inovações originais. Apesar do reconhecimento da importância das inovações incrementais, elas não têm recebido o mesmo tratamento que as inovações radicais, ou do tipo breakthrough, na literatura sobre gestão tecnológica. Provavelmente isso se deve ao fato de que parte delas resulta de atividades que se desenvolvem no âmbito da fábrica, do armazém ou do local de prestação dos serviços, através de atividades administrativas e operacionais que não possuem o mesmo glamour que as atividades de P\&D.

Essas atividades geradoras de melhorias em produtos e processos decorrem do aprendizado no trato com materiais, equipamentos, pessoas e informações, podendo ocorrer de modo espontâneo ou planejado. Esse aprendizado permite reduzir o custo unitário dos produtos, conforme o conhecido modelo da Curva de Aprendizado (Learning Curve ou Experience Curve), cujos primeiros estudos datam da década de 30 , sendo um dos mais importantes dessa fase inicial o realizado por Wrigh ${ }^{10}$ na indústria aeronáutica norte-americana. Porém, o reconhecimento da importância do aprendizado e sua popularidade no mundo acadêmico deve muito à obra de Arrow, ${ }^{11}$ prêmio Nobel de Economia em 1972. Para esse autor, as mudanças técnicas podem ser atribuídas ao aprendizado baseado na experiência proporcionada pelas atividades produtivas, daí a expressão learning by doing. No esquema de Arrow esse aprendizado é visto como uma decorrência espontânea do ato de produzir, sem a exigência de alocação de recursos específicos para obtê-lo.

A idéia de um aprendizado passivo do tipo by doing sofreu inúmeras críticas ten-
7. MARQUIS, Donald G. The anatomy of succeful inovations. In:ROTHBERG, R. R. (org). Corporate strategy and product innovation. N. York: The Free Press, 1981, p. 19-22.

8. BOOZ, ALLEN \& HAMILTON. New product management for the 1980s. New York: BA\&H, 1982.

9. BETZ, Frederick. Op. cit., p. 8.

10. Atribui-se a WRIGHT, T. P. o marco inicial do estudo desse fenômeno. Ele foi o primeiro a estudar sistematicamente 0 aprendizado na área produtiva baseado na experiência, sendo 0 artigo Factors affecting the cost of airplanes, publicado em 1936 no Journal of Aeronautical Science. Outras obras importantes sobre este tema que obtiveram ampla repercussão são as seguintes: HISCHMANN, W.B.. Profit from the learning curve. Harvard Business Review. v.42, n. 1: $p$ 125-139, Jan/Feb. 1964; BOSTON CONSULTING GROUP (BCG). Perspectives on experience. Boston: $B C G$, 1972; ABERNATHY W.J. \& WAYNE K. Limits of the learning curve. Harvard Business Review. v.52, n. 5, p.109-19, set./out. 1974,.

11. ARROW, Kenneth J.. The economic implication of learning by doing. Review of Economic Studies. v. 29, p. 155-173, June 1962. 
12. Techniques of value analysis and Engineering publicada pela McGraw-Hill Books, em 1965, é talvez uma das obras mais conhecidas de Lawrence D. MILES sobre análise de valor. No Brasil, destaca-se a obra de CSILLAG, João Mario. Análise do valor São Paulo: Atlas, 1986.

13. SHINGO apresenta o SMED em diversas obras, tal como em: A revolution in manufacturing: the SMED system. Cambridge, MA: Productivity Press , 1985.

14. SHINGO, Shigeo. $A$ revolution in manufacturing: the SMED system. Cambridge, MA: Productive Press, 1985, $p$. 29-30.

15. BELL, Martin. Learning and accumulation of industrial technological capacity in Developing Countries. In: FRANSMAN, Martin \& KING, Kenneth (eds). Technological capacity in the third world. New York: St. Martin Press, 1984 ; p. 191

16. ROSENBERG, Nathan. Inside the black box: tecnology and economics. New York: Cambridge University Press, 1982 , p. 120-3 do como base a experiência concreta das empresas, pois as reduções de custo observadas com a acumulação da produção devemse tanto às atividades rotineiras de produção e comercialização dos bens e serviços, quanto às atividades especificamente voltadas para melhorar o processo e o produto como, por exemplo, análises sistemáticas do processo produtivo para suprimir operações desnecessárias ou para realizá-las de modo mais eficiente. A análise do valor, por exemplo, pode ser entendida como uma técnica ou conjunto de técnicas voltadas especificamente para introduzir inovações incrementais. O objetivo básico da análise do valor, cujo desenvolvimento inicial deve-se aos trabalhos de Miles ${ }^{12}$ nas décadas de 40 e 50 , é oferecer aos consumidores produtos com utilidades e características equivalentes ou superiores aos que eram oferecidos e a um custo menor. Isso é obtido através de um enfoque criativo e organizado capaz de: 1) identificar as funções necessárias de um produto e 2) de encontrar meios alternativos para desempenhá-los a um menor custo, sem prejuízo da qualidade exigida.

A metodologia para realizar trocas rápidas de ferramentas, ou troca em menos de 10 minutos, conhecida pela sigla SMED Single-Minute Exchange of Die, desenvolvida por Shigeo Shingo ${ }^{13}$ desde a década de 50 , é outra das inúmeras abordagens para incrementar o aprendizado e introduzir melhorias no sistema produtivo. O primeiro estágio da metodologia deste autor consiste na distinção e separação das atividades de preparação de ferramentas em internas e externas. As primeiras são as que devem ser feitas necessariamente com as máquinas paradas (por exemplo, remoção de uma ferramenta e colocação de outra), enquanto que as atividades de preparação externas, como transporte da ferramenta, limpeza, afiação etc., podem ser realizadas com as máquinas em operação . De acordo com Shingo,${ }^{14}$ o tempo de preparação pode ser reduzir de 30 a $50 \%$, somente com a separação entre procedimentos internos e externos, mas isso ainda é insuficiente para alcançar os objetivos do SMED. Nos estágios seguintes procura-se converter as atividades de preparação internas em externas e aperfeiçoar todos os aspectos da preparação, tais como padronizar operações e eliminar os ajustes. Assim que os aperfeiçoamentos estiverem concluídos, o próximo desafio é realizar a troca com um toque apenas (OTED - OneTouch Exchange of Die). Os benefícios esperados de um programa de inovações nos processos produtivos para disseminar a troca rápida de ferramentas são, entre outros, o aumento da capacidade efetiva de produção e a possibilidade de produzir pequenos lotes de produtos diversificados para atender às demandas, à medida que elas se confirmam, sem elevar os custos. Constitui-se, portanto, num instrumento fundamental para promover níveis crescentes de sincronização da produção à demanda. Tanto a análise do valor quanto o SMED/OTED são métodos para ampliar os processos de aprendizado, o que significa dizer que são métodos para realizar inovações em produtos e processos, apesar de a literatura normalmente não os reconhecer como tais.

Bell, ${ }^{15}$ analisando o papel do aprendizado no processo de capacitação tecnológica de países em desenvolvimento, distingue cinco tipos de aprendizados: 1) o aprendizado obtido através das atividades de produção em curso na empresa (learning by operating); 2) o aprendizado obtido pela introdução de mudanças técnicas no aparato produtivo existente (learning by changing), através de atividades do tipo trouble-shooting; 3) o aprendizado pelo treinamento (learning by training); 4) pela contratação de profissionais que já possuem os conhecimentos que a empresa deseja (learning by hiring), e 5) o aprendizado obtido através das atividades de pesquisa em fontes de informações tecnológicas (learning by searching). Destes cinco, o primeiro é o que mais se aproxima do tipo descrito por Arrow pois, para Bell, tratase de um aprendizado que ocorre de modo relativamente passivo e automático. Os dois primeiros são os aprendizados baseados na produção (doing) e seus mecanismos de retroalimentação. Quando os seus limites são alcançados serão necessárias outras formas de aprendizado que se baseiam na aquisição de novos conhecimentos externos à empresa.

Rosenberg ${ }^{16}$ distingue no processo de inovação dois tipos de aprendizado: um, que é interno ao processo de produção, do tipo by doing, porém sem a conotação de passividade e automatismo da concepção arrowniana e, outro, que se obtém através 
da utilização do produto (learning by using). $\mathrm{O}$ uso continuado de um produto fornece elementos para proceder modificações no mesmo, bem como para especificar normas para a sua manutenção ou produção. No primeiro caso, esse aprendizado se materializa, incorpora-se fisicamente ao produto; no segundo, ele produz alterações na maneira de utilizá-lo. Embora Rosenberg afirme que o aprendizado pela utilização continuada é particularmente importante para a indústria aeronáutica, de bens de capital e de software, pode se generalizar para qualquer outra indústriantemfere6946ente dos demais, este último tipo de aprendizado tem seu foco centrado no usuário e isso vem de encontro a um tema recorrente no movimento da Qualidade Total: o de enfatizar a importância do cliente na definição da qualidade.

Atividades específicas para apressar $o$ aprendizado e introduzir melhorias, ou inovações incrementais, sempre existiram. Porém, verificase na atualidade profundas modificações no modo como essas atividades são concebidas e realizadas, configurando-se, dessa forma, uma nova postura em relação a elas. A grosso modo, pode-se distinguir duas posturas básicas: uma do tipo tradicional; e outra, afinada com o movimento da Qualidade Total. $\mathrm{Na}$ postura tradicional, os incrementos mais importantes resultam de tarefas episódicas e que ficam confinadas em áreas específicas (P\&D, Engenharia do Produto, O\&M, Grupo de Análise do Valor etc), de acordo com o princípio da segregação das funções, próprio do modo taylorista de organização. A nova postura enfatiza as melhorias contínuas que devem resultar do envolvimento de todos os integrantes da organização, incluindo fornecedores e clientes. Isso não significa que os setores especializados, a exemplo dos citados acima, deixem de ser o locus privilegiado da condução das inovações. Significa que a introdução de melhorias consti- tui uma tarefa permanente na qual todos devem dar a sua contribuição. Na postura tradicional a redução de custo é o seu leitmotiv básico, enquanto a nova postura tem como foco central a qualidade amplamente considerada, envolvendo produtos, processos, serviços e relacionamentos intra e interorganizacionais.

A Administração da Qualidade Total (TQM), que integra essa nova postura, pode ser entendida como uma concepção de administração que envolve todos os integrantes da organização e seus fornecedores num esforço contínuo para produzir e comercializar bens e serviços que atendam às expectativas dos seus clientes ou usuários. Uma das idéias básicas que orientam essa nova concepção administrativa é a da realização de melhorias contínuas em todas as instâncias da empresa, através da participação de todos os seus integrantes e colaboradores, para atender às demandas por qualidade, preço e variedade de produtos com a rapidez e a confiabilidade das entregas que o atual padrão de competitividade exige. Além da melhoria contínua, $o$ TQM tem como idéias fundamentais a focalização nos clientes, o envolvimentos de toda a força de trabalho e uma administração orientada para os processos administrativos e operacionais.

Para muitos autores, esta nova postura constitui a base da competitividade exibida pelas empresas japonesas. Hellwing, ${ }^{17}$ estudando as estratégias competitivas de empresas americanas e japonesas, afirma que estas últimas se preocupam mais com as inovações incrementais, em aprender com as falhas e focalizar suas atenções no processo produtivo, enquanto as norte-americanas, enfatizam a novidade dos produtos e as inovações do tipo breakthrough. Mansfield ${ }^{18}$ já havia notado que as empresas japonesas dão mais ênfase que as americanas em questões como ferramental, equipamentos e outros recursos de manu-
17. HELLWING, Helmut. Diferences in competitive strategies between the United States and Japan. IEEE Transactionon engineering Management. v. 39, n.1, p. $77-$ 8, fev 1992.

18. MANSFIELD, Edwin. Industrial inovation in Japan and the United States. Science. p. $1772-3,30$ set. 1988 . 
19. MOWERY Dawid \& ROSENBERG, Nathan Technology and the pursuit of economic growth. New York: Cambridge Press, 1989, p. 229-30.

20. IMAI, Masaaki. Kaizen: a estratégia para o sucesso competitivo. São Paulo: IMAM, 1988 fatura. Para Mowery \& Rosemberg, ${ }^{19}$ uma característica do processo de inovações das empresas japonesas é a adoção de uma estratégia incrementalista que intensifica as atividades para identificar as falhas dos produtos, as preferências dos consumidores e os recursos tecnológicos mais adequados, sempre procurando aproximar o máximo possível as áreas de manufatura e de desenvolvimento de produtos e processos.

Referências sobre a competitividade das empresas japonesas devem ser tomadas com reservas, quando associadas apenas às considerações de ordem interna das empresas, tal como a postura incrementalista acima mencionada. Existem diversas fontes de competitividade macroorientadas que, geralmente, não são consideradas nos estudos que tratam das práticas administrativas e operacionais das empresas japonesas. Uma importante fonte de competitividade das empresas japonesas resulta das políticas de inovação conduzidas pelo MITI (Ministry of International Trade and Industry), que tem se encarregado de coordenar o processo de seleção das áreas tecnológicas a serem incentivadas, bem como das empresas que devem participar dos projetos para desenvolvê-las. Uma orientação típica desse órgão tem sido a de restringir o número de empresas que podem participar desses projetos, no sentido de evitar tanto o monopólio, quanto a concorrência predatória de uma indústria mais atomizada, dois tipos de mercado que tendem a desestimular os investimentos em inovações de vulto, por motivos diferentes. Neste último tipo, esse desestímulo decorre da dificuldade de gerar fundos para sustentar os projetos de inovações, face à redução dos lucros das empresas como decorrência de uma competição mais acirrada; o desestímulo às inovações na empresa monopolista resulta da comodidade decorrente de ser a única do lado da oferta. Outras medidas adotadas pelo governo japonês para estimular as inovações incluem a proteção aos mercados internos e o apoio às exportações para as empresas inovadoras. Questões como essas não retiram a importância das práticas incrementalistas como fontes de competitividade das empresas. Mas advertem para o fato de que só isso não basta. Pode-se dizer, no entanto, que essas novas concepções administrativas que enfatizam as melhorias contínuas e, por conseguinte, a participação de todos os membros da organização constituem condições necessárias para se obter elevados padrões de competitividade.

\section{Melhoria Contínua}

Como diz Imai, ${ }^{20}$ a essência das práticas japonesas de administrar (TQM, JIT etc) pode ser reduzida a uma palavra, kaizen, que significa melhoramento contínuo envolvendo todos, administradores e operários, em todas as instâncias da vida. Esse autor, cujo trabalho popularizou a palavra kaizen, ressalta que o termo melhoramento no contexto da administração acidental significa freqüentemente melhoramentos em equipamentos, excluindo os elementos humanos. Kaizen, enquanto melhoramento é um conceito genérico que se aplica $a$ todas as atividades de todos. Para Imai, existem duas estratégias ou enfoques contrastantes para implementar o progresso técnico: o enfoque gradual ou da melhoria contínua e o dos grandes saltos ou das inovações. Como mostra o autor acima, esses enfoques não são excludentes, ao contrário, eles se interagem de modo recíproco. Ou seja, sempre que ocorre uma inovação, a mesma deve ser melhorada continuamente para que o novo padrão de desempenho não só corresponda ao esperado, mas até supere as expectativas originais. Em outras palavras, as inovações incrementais realizadas sob qualquer enfo- 
que, tradicional ou das melhorias contínuas, não existem enquanto entidades autônomas, mas sim como etapas fundamentais da implementação de inovações maiores em produtos e em processos. Não há, portanto, incompatibilidades nem antagonismos entre inovações radicais e melhorias.

A propósito, de acordo com a Fundação para o Prêmio Nacional da Qualidade (FPNQ), a expressão $m e$ lhoria contínua refere-se tanto às melhorias incrementais quanto às revolucionárias (inovação). Para esta entidade, a melhoria precisa estar impregnada pelo modo de funcionamento da organização, ou seja, ela deve ser parte do dia-a-dia de todos os setores, deve buscar a eliminação dos problemas em suas origens e ser motivada pelas oportunidades de melhor executar uma atividade ou pelos problemas que necessitam de solução. Ainda conforme a FPNQ, as oportunidades de melhorias incluem sugestões dos funcionários, $\mathrm{P} \& \mathrm{D}$, informações dos clientes e comparações com referências de excelência e outras formas para comparar desempenho. Exemplos de melhorias citadas pela FPNQ : aumento do valor para o cliente através de produtos novos ou melhorados; redução de erros, defeitos e desperdícios; rapidez de resposta; incremento da produtividade; melhoria do desempenho e da posição de liderança da organização no cumprimento das suas responsabilidades. Como se vê, esta entidade que, desde 1992, confere anualmente o Prêmio Nacional da Qualidade, apresenta um entendimento mais abrangente de melhoria contínua, não se limitando ao conceito de inovação de pequena monta, conforme se depreende, por exemplo, dos textos de Marquis e Betz, citados anteriormente.

A idéia de melhoramentos contínuos não é nova e entre seus principais promotores estão os grandes gurus do Movimento da Qualidade. Esta idéia permeia praticamente toda a extensa obra de Juran, ${ }^{21}$ como, por exemplo, no seu conhecido conceito de Espiral do Progresso da Qualidade ou na
Trilogia da Qualidade, a saber: 1) planejamento da qualidade; 2) controle da qualidade durante as operações e 3) melhoramento da qualidade. Criar a consciência da necessidade e da oportunidade de melhorar é um dos dez pontos ou princípios de Juran. O primeiro dos 14 pontos de Deming ${ }^{22}$ pode ser assim enunciado: estabelecer como objetivo permanente o aperfeiçoamento de produtos. O ciclo PDCA, (do inglês: PlanDo-Check-Action), desenvolvido por Shewart ${ }^{23}$ na década de 30 e popularizado através da obra de Deming, mostra a necessidade de um tratamento permanente em relação à qualidade, contrapondo-se, dessa forma, às idéias de objetivos e padrões fixos ou de níveis aceitáveis de qualidade estáticos. Os objetos de estudo dos ciclos PDCA são os processos e não as atividades ou seções isoladamente consideradas. Esses ciclos podem ser entendidos como metodologias básicas para se alcançar permanentemente novos padrões de desempenho. Assim que um certo padrão é alcançado, já se torna objeto de novos estudos, ou seja, o ciclo se repete, inicialmente para sustentar o padrão alcançado, depois, para superá-lo.

Estes são apenas alguns exemplos de práticas voltadas para a obtenção de inovações incrementais em bases contínuas. Práticas como essas intensificam a realização de melhorias nas tecnologias existentes e favorecem a introdução de novas. $E$ tanto podem ser aplicadas com respeito às inovações em produtos e processos de produção, quanto às de caráter organizacional, tais como, modificações na estrutura organizacional da empresa ou no modo de relacionamento com os fornecedores. Uma postura voltada para a melhoria contínua pode contribuir para reduzir ou solucionar conflitos entre os diferentes segmentos da organização como, por exemplo, os inúmeros conflitos entre as áreas de produção, de marketing e de projeto que frequientemente surgem durante a introdução de novos equipamentos produtivos ou novos produtos.
21. JURAN, Joseph J. On planning for quality. NewYork: The Free Press, $1988 ; p$ 1-7. Veja também: The quality trilogy: a universal approach to to managing for quality. Juran Institute Inc, 1986; JURAN, J.J. \& GRYNA, F.M. Quality Control Handbook. NewYork: McGraw-Hill, s.d.

22. DEMING, W.Edward. Quality, productivity and competitive position. Cambridge, MA: MIT Press, 1987. Veja também : GITLOW, Howard S. \& GITLOW, Shelly J. The Deming guide to quality and competitive position. New Jersey: Prentice Hall, 1987; WALTON, Mary. Método Deming na prática. Rio de Janeiro: Campus,1990.

23. Walter A. SHEWART introduziu o controle estatístico de qualidade no inicio da décade de 30 nos Bell Telephone Laboratories. Ele recomendava atenção especial para as causas e 0 controle das variabilidades. Sua obra mais conhecida é Economic control of quality of manufctured product. New York: Van Nostrand, 1931. 
24. FLEURY, Afonso C.C. Automação na indústria mental- mecânica: tendências da organização do trabalho $e$ da produção. Revista de Administração. São Paulo, v.24, n.3, p. 39-51, jul./set. 1989.

25. FLEURY, Afonso C. C. idem, p. 45.

26. SKINNER, Wickham. The focused factory. Harvard Business Review.p. 113-121. may/june 1974

27. STALK, George Jr. . Timethe next source of competitive advantage. In: Harvard Business Review. p. 43, July/ Aug. 1998

\section{CONTRIBUIÇÕES DAS ÁREAS PRODUTIVAS}

A introdução de melhorias contínuas em todas as instâncias da empresa exige práticas administrativas voltadas para criar e manter um ambiente interno altamente motivado e com as habilidades necessárias para realizá-las. Para Fleury, ${ }^{24}$ o novo modelo de empresa produtiva é a empresa integrada e flexível capaz de responder com eficácia as rápidas mudanças que ocorrem no ambiente. Analisando mais especificamente o setor metal-mecânico, Fleury identifica quatro novas técnicas organizacionais associadas ao novo padrão de organização da produção, a saber: programas de qualidade, tecnologia de grupo, manufatura celular e o Just-in-Time (JIT). As primeiras são as que introduzem as inovações mais importantes, pois envolvem não só conceitos técnicos, mas também questões de natureza comportamental; seu objetivo final é obter o comprometimento das pessoas para com a empresa e seus produtos, para maximizar a produtividade e a qualidade. Esses programas de qualidade formam, segundo Fleury, o cenário no qual se desenvolvem as outras três técnicas.

A Tecnologia de Grupo (TG) e a manufatura celular referem-se às esferas do produto e da produção, respectivamente, conforme Fleury. ${ }^{25}$ $O$ agrupamento de peças por similaridade de formas ou de processos de fabricação favorece a redução da variedade de peças e a padronização de formas e operações. Ao diminuir a variedade de peças obtém-se uma redução do número de processos e, conseqüentemente, de instruções, facilitando a fabricação e a montagem e diminuindo as fontes de erros. E torna mais rápida a introdução de novas peças na família, quando for necessário. As células de manufaturas dedicadas a essas famílias de peças similares, por sua vez, proporcionam reduções no tempo de preparação e, consequientemente, no tempo total de fabricação, além de facilitarem os processos de melhoramento da qualidade sem elevar custos à medida que as suas atividades passam a apresentar um elevado grau de homogeneidade e repetitividade. Dito de outra forma, estas células desenvolvem atividades altamente focalizadas. Vale lembrar que para Skinner, ${ }^{26}$ em obra seminal sobre as dimensões competitivas da área de produção, a manufatura focalizada constitui um dos principais instrumentos para elevar a produtividade e baseia-se na idéia de que a simplicidade, a repetição, a experiência e a homogeneidade das tarefas produzem competência.

A TG pode ser aplicada em firmas que oferecem uma grande variedade de produtos constituídos por partes discretas e produzidos em pequenos e médios lotes. Ela permite que esse tipo de sistema produtivo passe a ter certas vantagens típicas da produção em massa sem perder a flexibilidade para suportar uma linha de produtos bastante variada. Ou seja, permite romper com o tradicional trade-off entre produtividade via escala de produção e flexibilidade para produzir uma grande variedade de produtos em pequenos lotes. Stalk, ${ }^{27}$ em obra muito citada, mostra que tradicionalmente os custos aumentam as taxas de 20 a $30 \%$ quando a variedade dobra, enquanto os custos diminuem de 15 a $25 \%$ quando o volume de produção dobra. Um sistema flexível de manufatura combina uma grande variedade de produtos com baixo custo. Para este autor, as novas gerações de empresas competem com manufaturas flexíveis e sistemas altamente responsivos às necessidades do mercado, fazendo com que elas aumentem a variedade e incrementem as inovações sem aumentar os custos de produção. Isso exige modificacões substanciais na maneira de gerir a produção e introduzir inovações.

As práticas JIT podem contribuir para se obter redução de peças e processos, ao 
mesmo tempo em que oferecem ao mercado uma grande variedade de produtos. Impulsionam as melhorias contínuas com o objetivo de eliminar todo tipo de desperdício ou de atividades que não adicionam valor ao produto, segundo a ótica do mercado. $\mathrm{Na}$ elaboração do projeto de novos produtos, as práticas JIT recomendam a simplificação e o uso de peças e componentes já projetados para os produtos existentes, com o objetivo de oferecer ao mercado a variedade que ele deseja sem, no entanto, aumentar a variedade de processos de fabricação. Isso exige que se leve em consideração os recursos produtivos existentes, incluindo os dos fornecedores, para tornar o projeto manufaturável. $\mathrm{O}$ uso de projetos modulares para gerar peças comuns a vários produtos e projetos para a manufatura e a montagem permitem que a empresa alcance simultaneamente economias de escalas e de escopo. Isso estimula a introdução de diferenciações nos produtos para atender diferentes segmentos do mercado, através de lotes de fabricação menores e à medida que a demanda se verifica, sem perder as vantagens da produção em massa em termos de produtividade.

A realização de projetos com manufaturabilidade, levando-se em conta prazos, custos, recursos existentes e as expectativas dos clientes, exige uma nova postura metodológica em relação às inovações. $\mathrm{Na}$ visão tradicional, também decorrente da orientação segregacionista da organização taylorista, a inovação para introduzir um novo produto se dá através de um processo seqüencial, iniciando com as atividades para identificar, pesquisar e avaliar as idéias para solucionar problemas ou aproveitar oportunidades de mercado, fluindo depois para as de projeto e implantação e destas para as de produção e introdução comercial, conforme esquematizado na figura 1. Quando ocorre algum problema ou dificuldade numa fase da inovação, como na elaboração das especificações do produto não se atendeu completamente as recomendações provenientes das pesquisas mercadológicas, as alterações a serem feitas pela área técnica que gerou o problema tendem a ficar em segundo plano, pois o seu pessoal, via de regra, já se encontra envolvido com as atividades das outras inovações em curso na empresa. As conseqüências são conhecidas: perda de tempo, desperdício de recursos, es- forços para encontrar os culpados, conflitos entre as diversas áreas, dificuldades para atender as exigências dos consumidores e aumento dos custos. Como se sabe, os custos para efetuar modificações crescem à medida que as etapas do processo de inovação se consolidam. A tabela 2, publicada na Business Week, ${ }^{28}$ exemplifica este fato para produtos eletrônicos; ou seja, o custo de uma alteração cresce dez vezes mais de uma etapa para a outra subseqüente. Embora os dados da tabela 2 referem-se especificamente às inovações em produtos eletrônicos, um comportamento semelhante a este pode ser estendido de modo genérico para todas as inovações importantes de todas as áreas técnicas.

FIGURA 1

INTRODUÇÃO DE UM NOVO PRODUTO - abordagem tradicional

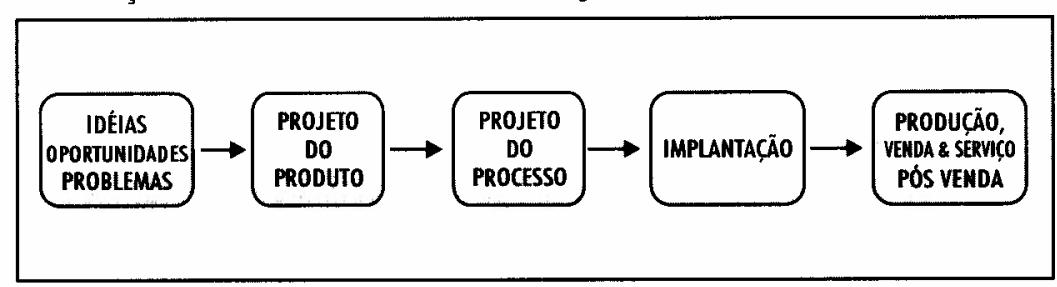

Uma postura mais apropriada ao movimento da Qualidade Total exige que as etapas de uma inovação sejam executadas com a maior simultaneidade possível, daí as expressões engenharia simultânea, paralela ou concorrente, para indicar esse novo processo de inovação tecnológica. Essa maneira de conceber o processo de inovação, em que produto e processo são concebidos e desenvolvidos de modo interativo, como ilustra a figura 2 , reduz tempo, necessidades de recursos e conflitos através de uma intensa articulação entre os diferentes profissionais envolvidos no processo de inovação. Para isso, torna-se necessária uma nova organização do trabalho que favoreça a interação multifuncional para integrar num mesmo projeto pessoas ligadas às atividades de desenvolvimento do produto e do processo, de produção, de marketing, de recursos humanos, de custo, de compras etc. e, conforme o caso, representantes dos fornecedores, formando células de projeto, ou células de engenharia. É necessária também a utilização intensiva de recursos da Tecnologia de Informação (TI), como estações CAE/CAD/CAM interligadas em rede para que as informações so-
28. BUSINESS WEEK. A Smarter way to manufacture (special report). p. 64-9, 30 April 1990. 
bre o produto, os seus meios de produção e as necessidades dos clientes geradas por um grupo de profissionais de um projeto de inovação específico possam ser rapidamente compartilhadas pelos demais. A disponibilização de informações e a integração multifuncional constituem, portanto, précondições necessárias nesta nova metodologia de inovações.

TABELA 2

Custo das mudanças durante o desenvolvimento de um produto eletrônico importante em processo tradicional de inovaçâa.

\begin{tabular}{|l|r|}
\hline QUANDO AS MUDANÇS SÃO FEITAS & CUSTO (em USS) \\
\hline Durante o projeto & $1,000.00$ \\
Durante os testes do projeto & $10,000.00$ \\
Durante o planejamento do processo & $100,000.00$ \\
Durante os testes de produção & $1,000,000.00$ \\
Durante o produçõo final & $10,000,000.00$ \\
\hline
\end{tabular}

Fonte: BUSINESS WEEK . A smarter way to manufacture. Special report. 30 April 1990, p.64.(Apud.: Dataquest, Inc.)

O MRP-II (Manufacturing Resources Planning) é outro sistema de gestão da produção que também favorece a introdução de inovações na empresa. Enquanto sistema integrado de administração auxiliado por computador, o MRP-II permite uma visão global da empresa e um tratamento completo de todos os recursos de produção, dando condições de planejar estratégicamente as mudanças que o ambiente pode exigir no futuro. Esse sistema permite a realização de simulações para analisar os impactos da introdução de um novo produto, ou de alterações nos produtos existentes, sob diversos aspectos, tais como custo, capacidade, posição dos estoques, atendimento das ordens de produção em andamento etc., com o objetivo de identificar restrições e estabelecer planos de produção realísticos. Visto sob esta perspectiva, este é um sistema próativo e, dessa forma, bastante apropriado para atuar em ambientes produtivos dinâmicos e competitivos. A capacidade de responder às mudanças do ambiente é um dos seus principais pontos fortes. Este sistema pode dar a sua melhor contribuição em empresas manufatureiras que produzem bens com elevado grau de complexidade e sujeitos a freqüentes alterações. Além disso, pode conviver de modo integrado com as técnicas JIT, pois tratam-se de abordagens diferentes e em muitos aspectos complementares.
FIGURA 2 INTRODUÇÃO DE UM NOVO PRODUTO

Nova abordagem

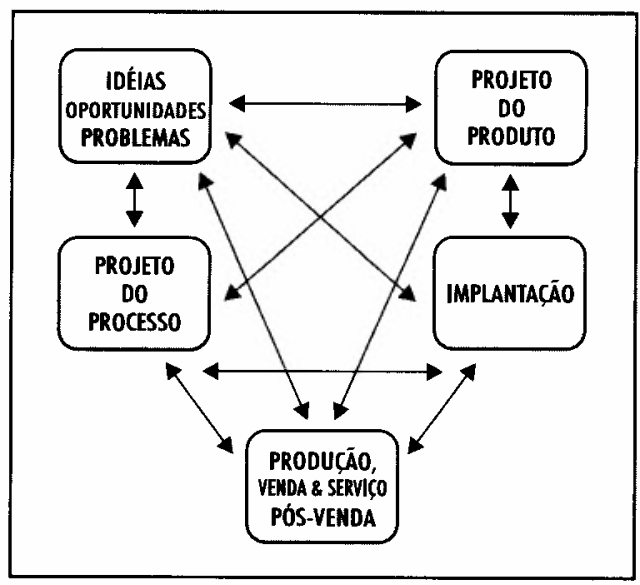

De fato, os componentes do MRP-II são instrumentos de planejamento, enquanto as práticas e técnicas JIT-Just-in-Time - traduzem uma concepção administrativa integral que influencia todas as atividades da empresa com o objetivo de reduzir ao máximo os desperdício de materiais, de tempo, de espaço, de habilidades etc. Mas, por outro lado, apresenta-se insatisfatório quando se trata de planejar mudanças de vulto, uma vez que sua preocupação central é produzir conforme a demanda o que os clientes estão querendo no momento. $\mathrm{Na}$ sua essência, o JIT, como sistema de puxar a produção, não é pró-ativo quando se amplia o horizonte de planejamento, embora isso pode ser corrigido até certo ponto como, por exemplo, através de projetos modulares para planejar a introdução de novos produtos, conforme mencionado. Mesmo assim, as etapas de planejamento nos níveis superiores, como planejamento agregado, planejamento da capacidade, da expansão, financeiro etc., podem ficar descobertos. O MRP-II permite uma visão global da empresa e um tratamento completo de todos os recursos de produção, dando condições de planejar estrategicamente as mudanças que o ambiente pode exigir no futuro.

A interação de elementos do MRP-II, como instrumentos de planejamento, com as práticas JIT tem sido possível graças aos aperfeiçoamentos constantes da tecnologia de informação e da própria concepção dos sistemas de MRP, que conta hoje com módulos de interface com o kanban e ou- 
tros elementos do JIT. Cabe ressaltar que a redução da complexidade administrativa e operacional resultante de um ambiente JIT facilita a implantação e operacionalização dos componentes do MRP-II, bem como de outros elementos de automação industrial como CAD, CAM, robótica etc. A introdução do MRP, integrados ou não às práticas JIT, exige revisão dos processos administrativos e operacionais, incluindo a definição de cargos e atribuição de responsabilidades. Sem isso, a empresa pode colher resultados contrários aos esperados, pois as ineficiências serão explodidas pelo sistema. Essa é uma preocupação válida para qualquer sistema de gestão, pois a qualidade das saídas depende da qualidade das entradas, por melhor que seja o seu processo de conversão.

As práticas administrativas e operacionais baseadas na Teoria das Restrições (TOC - Teory of Constraints), desenvolvida por Goldratt, ${ }^{29}$ na medida em que centra sua atenção sobre os elos mais fracos como as restrições do sistema, introduz uma nova abordagem de focalização que se soma às demais baseadas na simplificação, repetição e homogeneização, antes comentadas. Identificando as restrições do sistema produtivo e ajustando os demais recursos a elas, pode-se concentrar a atenção para elevar a capacidade das restrições. Essa prática evita a dispersão de esforços ao focalizar as atividades para produzir melhorias (análise de valor, SMED etc.) naqueles centros que representam restrições ao sistema, pois são estes centros que condicionam as possibilidade de aumentar os ganhos que, segundo Goldratt, é a diferença entre o que a empresa recebe pelas vendas e o que ela paga aos fornecedores. Melhorias em outros centros que não constituem restrições podem ser apenas ilusórias, segundo um dos princípio dessa Teoria. Cabe lembrar que as restrições podem estar situadas no âmbito dos fornecedores, ou no mercado consumidor, e não apenas no aparato produtivo. Assim, pode-se dizer que a Teoria das Restrições também fornece elementos para conceber práticas administrativas e operacionais voltadas para otimizar a realização de melhorias contínuas, pois identifica e explora os locais onde essas melhorias realmente podem contribuir para os resul- tados da empresa como um todo num dado momento.

\section{CONCLUSÃO}

A área produtiva de uma empresa tem um importante papel a desempenhar nos processos de inovação tecnológica. O uso de instrumentos apropriados de gestão da produção favorece a realização de inovações tecnológicas de vulto e facilita a introdução de melhorias no produto ou no processo inovado. A possibilidade de obter os benefícios esperados da introdução de novos produtos ou processo que incorporem novas tecnologias depende, em grande parte, de práticas administrativas e operacionais pertinentes à área de produção. As novas concepções e práticas administrativas e operacionais ligadas ao movimento da Qualidade Total contribuem para reduzir as distâncias comportamentais e operacionais entre o pessoal das áreas de produção e o da equipe responsável pelo projeto de inovação.

Não cabe aqui discutir se as técnicas e práticas tratadas acima, especialmente $o$ JIT, representam verdadeiras rupturas com as concepções de gestão do tipo tayloristafordista, ou se, ao contrário, tratam-se de continuações aperfeiçoadas e afinadas com os novos tempos. O fato é que elas exigem modificações na maneira de administrar, comparativamente as formas tradicionais. A utilização destas técnicas e a possibilidade de realizar melhorias contínuas de acordo com os conceitos de Kaizen exigem novos comprometimentos com todos os integrantes da organização e seus parceiros. Essas práticas enfatizam as soluções coletivas no processo de inovação tecnológica em todas as suas fases. Para isso torna-se necessário a realização de inovações de caráter administrativo. Organizações achatadas, valorização da força de trabalho, ampliação das habilidades, integração funcional, novas formas de entender as relações entre autoridade e responsabilidade são alguns elementos de caráter administrativo necessários para que a incorporação de novas tecnologias dentro de um ambiente altamente competitivo, como o que se verifica na atualidade, possam produzir os benefícios que delas se esperam.
29. Elementos da Teoria das Restrições podem ser encontradas em GOLDRATT, Eliyahu M. A sindrome do palheiro: garimpando informações num oceano de dados. São Paulo: IMAM, 1991. 